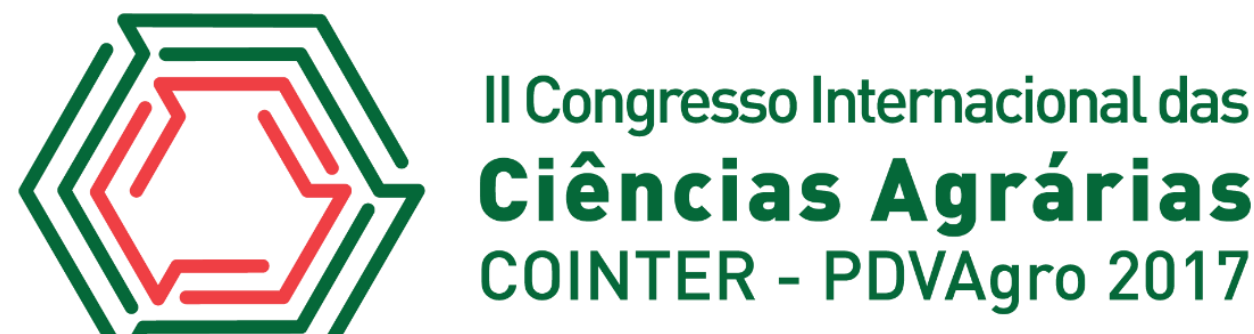

\section{ANÁLISE DO ESTRATO HERBÁCEO EM DIFERENTES ESTÁGIOS SUCESSIONAIS DE FLORESTAS NATURAIS DA CAATINGA}

\author{
Apresentação: Pôster
}

\begin{abstract}
Anderson Aurelio de Azevêdo Carnaval ${ }^{1}$; Bruna Rafaella da Silva ${ }^{2}$; Márcia Gabrielle de Almeida Cardoso ${ }^{3}$; João Paulo Silva Gomes ${ }^{4}$; Tatiane Kelly Barbosa de Azevêdo ${ }^{5}$
\end{abstract}

\section{Introdução}

O bioma Caatinga apresenta vegetação tropical xerófila com predominância de espécies decíduas, e um clima sazonal de curta estação chuvosa, oscilando entre 3 e 6 meses, com precipitações médias anuais variando entre 380 e $800 \mathrm{~mm}$ ano (WWF, 2017). Esta sazonalidade climática exerce forte influência sobre a composição de espécies no bioma caatinga, e apresentam uma relação direta com a estrutura do componente herbáceo, uma vez que se torna ausente no período seco, surgindo com maior frequência na estação chuvosa (FEITOZA, 2004).

Existe uma deficiência de informações quanto a cobertura vegetal do bioma caatinga, e quando se trata de herbáceas essa carência é ainda maior, no entanto esse conhecimento é importante para que sejam traçadas estratégias de utilização dos seus recursos de forma sustentável (ANDRADE et al., 2008). Araújo Filho e Crispim, (2003) afirmam que durante a estação das chuvas, a maior parte da forragem é proporcionada pelo estrato herbáceo, com baixa participação da folhagem de árvores e arbustos. Porém, existem poucos estudos na literatura com relação a avaliação qualitativa dos nutrientes presentes neste componente vegetal, que é de fundamental importância para a seleção de espécies com potencial forrageiro. Diante disto, este trabalho teve como objetivo, identificar o extrato herbáceo localizados em diferentes estágios sucessionais de florestas naturais na caatinga, e analisar suas características nutricionais.

\footnotetext{
${ }^{1}$ Engenharia Florestal, Universidade Federal do Rio Grande do Norte, carnaval552@ufrn.edu.br

${ }^{2}$ Engenharia Florestal, Universidade Federal do Rio Grande do Norte, brunarafaellaf@hotmail.com

${ }^{3}$ Engenharia Florestal, Universidade Federal do Rio Grande do Norte, marcia.gabrielle@gmail.com

${ }^{4}$ Engenharia Florestal, Universidade Federal do Rio Grande do Norte, jpgoms@hotmail.com

${ }^{5}$ Professora Doutora, Universidade Federal do Rio Grande do Norte, tatianekellyengenheira@hotmail.com
} 


\section{Fundamentação Teórica}

Em regiões de clima semiárido como a Caatinga, normalmente, a disponibilidade de gramíneas e de dicotiledôneas herbáceas é altamente influenciada pelas condições climáticas (ARAÚJO FILHO et al., 1996), especialmente com relação à estação chuvosa, seja quanto à intensidade, seja com relação à frequência; ou quanto à distribuição das chuvas ao longo do ano.

Durante o período chuvoso, as forrageiras anuais dominantes na vegetação herbácea da caatinga, apresentam um crescimento rápido, diferenciam-se pela duração de seu ciclo fenológico, o que resulta em uma forte periodicidade e excesso de forragem no período (SILVA et al., 1999). Segundo Santana e Souto (2006), durante a estação das chuvas, a maior parte da forragem é proporcionada pelo estrato herbáceo, com baixa participação da folhagem de árvores e arbustos, porém, poucos estudos são realizados visualizando este potencial.

\section{Metodologia}

O trabalho foi desenvolvido em parcelas de 20 x 20m de três diferentes estágios sucessionais arbóreos, sendo eles classificados como jovem, intermediário e adulto e, as parcelas georreferenciadas.

A coleta das herbáceas foi realizada durante período chuvoso, onde foram alocadas ao acaso, dentro de cada sub parcelas 2 mini parcelas de 2 x $2 \mathrm{~m}$ onde uma se localizou abaixo da copa e outra fora da copa, totalizando 18 mini parcelas, sendo 6 para o estágio sucessional jovem, 6 para o estágio sucessional intermediário e 6 para o estágio sucessional adulto. As espécies foram identificadas por comparações de exsicatas depositadas no herbário da UFCG/CSTR/UACB, e com o auxílio de chaves taxonômicas e de literatura específica.

Para quantificação da matéria seca do estrato herbáceo, foi utilizada uma moldura de ferro chato, de 0,5m x 0,5m adaptado de Araújo Filho et al. (1986), distribuída ao acaso dentro de cada mini parcela experimental, sendo os valores médios expressos por hectare. Os componentes do estrato herbáceo foram cortados rente ao solo, colocados em sacos de papel e pesados. Ao final de cada coleta, as amostras foram levadas para uma estufa de circulação forçada de ar, a $65^{\circ} \mathrm{C}$, por 48 horas, para a obtenção do peso do material pré-seco, posteriormente moídas e encaminhadas para o Laboratório de Nutrição Animal/CSTR/UFCG para determinação da qualidade da forragem. As variáveis avaliadas foram: composição botânica; produção de fitomassa (corte e pesagem), e 
qualidade forrageira, sendo avaliado: FDN (fibra em detergente neutro), FDA (fibra em detergente ácido), PB (proteína bruta), MO (matéria orgânica) E MM (matéria mineral) (SILVA, 1998).

\section{Resultados e Discussões}

Nos estágios sucessionais foram encontrados basicamente a Malva branca que é um subarbusto e o Campim panasco considerado herbácea (Tabela 2).

Tabela 2: Espécies encontradas nos estágios sucessionais jovem, intermediário e adulto. Fonte: Própria

\begin{tabular}{cc}
\hline Nome comum & Nome científico \\
\hline Malva branca & Sida cordifolia L. \\
Capim panasco & Aristida setifolia H.B.K. \\
\hline
\end{tabular}

Na figura 1, é possível observar a quantidade de Matéria seca encontrada A.C. (abaixo da copa) e F.C. (fora da copa) em kg/ha, mostrando que no estágio sucessional jovem coletado F.C. encontrou-se uma maior quantidade de matéria seca que os demais, seguido da coleta A.C. no mesmo estágio.

Figura 1: Matéria seca das espécies coletadas A.C. (abaixo da copa) e F.C. (fora da copa) em três estágios sucessionais de caatinga. Fonte: Própria

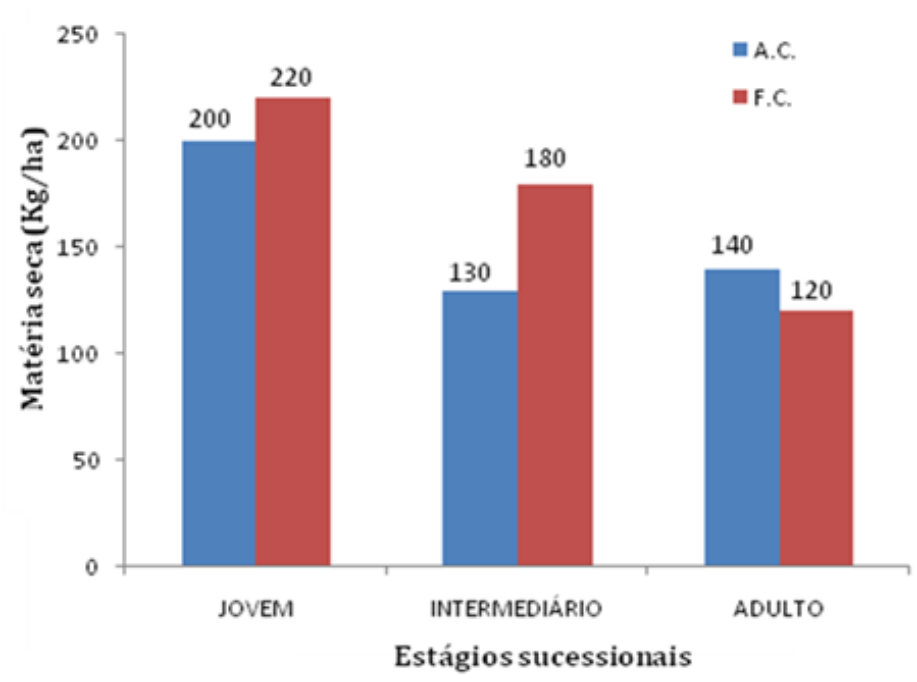

O estágio sucessional adulto apresentou menor quantidade de matéria seca, visto a baixa luminosidade encontrada no estágio sucessional adulto, o que podem ser explicados devido o tipo de vegetação herbácea, que é predominante em ambientes com incidência de raios solares. Estes resultados vêem corroborar com os obtidos por Araújo Filho et al., 2002 quando avaliaram a disponibilidade de fitomassa do estrato herbáceo em caatinga raleada, obtendo resultados de 283,5 
$\mathrm{kg} / \mathrm{ha}$ no final do período de estiagem, valores aproximados aos do estágio sucessional jovem, principalmente encontrados F.C..

Na tabela 2 é possível observar os valores médios de FDN (Fibra em Detergente Neutro) e FDA (Fibra em Detergente Ácido) avaliados estatisticamente.

Tabela 2: Valores médios de FDN (Fibra em Detergente Neutro) e FDA (Fibra em Detergente Ácido) encontrados nos estágios sucessionais. Fonte: Própria

\begin{tabular}{ccc}
\hline & FDN (\%) & FDA (\%) \\
\hline Jovem & $75,27 \mathrm{a}$ & $55,52 \mathrm{a}$ \\
Intermediário & $64,30 \mathrm{~b}$ & $53,50 \mathrm{a}$ \\
Adulto & $63,83 \mathrm{~b}$ & $50,21 \mathrm{a}$ \\
\hline
\end{tabular}

*Médias seguidas por letras minúsculas iguais, na mesma coluna, não diferem entre si $(\mathrm{P}<0,05)$.

Na avaliação do FDN o efeito dos fatores foi independente $(P>0,05)$, não houve diferença significativa na cobertura, entretanto, houve diferença nos tratamentos. Observa-se que o teor de FDN foi maior para a planta jovem $(75,27)$ em relação aos demais estágios sucessionais que não diferiram entre si, isto pode ter ocorrido pela grande presença de Malva branca nestas áreas, na qual são espécies com maior quantidade de fibras. Quanto ao FDA não houve efeito dos tratamentos (P > $0,05)$.

Os valores referente a hemicelulose podem ser encontrados na tabela 3. Verifica-se que o efeito dos fatores foram dependentes $(\mathrm{P}>0,005)$. Nos estágios sucessionais fora da copa, observouse que as plantas jovens apresentaram um teor de hemicelulose superior ao estágio intermediário e adulto, que por sua vez não diferiram entre si.

Tabela 3: Valores médios de hemicelulose encontrados nos estágios sucessionais jovem, intermediário e adulto em duas posições A.C. (abaixo da copa) e F.C.(fora da copa). Fonte: Própria

HEMICELULOSE $(\%)$

\begin{tabular}{llll}
\hline & Jovem & Intermediário & Adulto \\
FC & 24,93 a A & 11,25 a B & 12,15 a B \\
AC & 14,57 a A & 10,35 a A & 15,07 a A
\end{tabular}

Médias seguidas da mesma letra minúscula entre linhas e minúsculas entre colunas não diferem significativamente pelo teste de Tukey $(\mathrm{P}>0,05)$.

Quanto a Matéria orgânica $(43,35)$ e Matéria Mineral $(6,64)$, verifica-se que os valores analisados não interferiram nesta variável $(\mathrm{P}>0,05)$. Analisando o teor de Proteína das plantas observa-se que os efeitos dos fatores foram independentes $(\mathrm{P}>0,05)$. Pelos dados apresentados 
verifica-se que as plantas no estágio intermediário $(6,65)$ apresentam teores de Proteínas superiores ao do estágio sucessional jovem $(5,01)$ e estas não diferiram do estágio sucessional adulto $(5,57)$.

De acordo com a tabela 3, percebe-se que o estágio sucessional jovem se destaca em termos de nutrientes de modo geral, comprovando o elevado teor de Proteína neste estágio.

\section{Conclusões}

Não houve variação de espécies herbáceas em função do estágio sussecional arbóreo. O estrato herbáceo presente no estágio sucessional jovem coletado fora da copa apresenta maior quantidade de matéria seca/ha, porém seu teor proteico é inferior ao estágio intermediário.

\section{Referências}

ARAÚJO FILHO, J. A. e CRISPIM, S. M. A. Pastoreio combinado de bovinos, caprinos e ovinos em áreas de Caatinga no Nordeste do Brasil. In: CONFERÊNCIA VIRTUAL GLOBAL SOBRE PRODUÇÃO ORGÂNICA DE BOVINOS DE CORTE, 1. 2003, Corumbá. Anais eletrônicos... Corumbá: Embrapa Pantanal: Universidade do Contestado, 2003.

ARAÚJO FILHO, J.A.; GADELHA, J.A.; LEITE, E.R.; SOUZA, P.Z. Composição botânica e química da dieta de ovinos e caprinos em pastejo combinado na região dos Inhamuns, Ceará. Revista da Sociedade Brasileira de Zootecnia, v.25, n.3, p.383-395, 1996.

SANTANA, J.A.S.; SOUTO, J.S. Diversidade e Estrutura Fitossociológica da Caatinga na Estação Ecológica do Seridó-RN. Revista de Biologia e Ciências da Terra, v. 6, n. 2, p. 232-242, 2006.

SILVA, D. J. Análise de alimentos (Métodos Químicos e Biológicos). Viçosa, Minas Gerais. p. $166,1998$.

SILVA, N. L.; ARAUJO FILHO, J. A.; SOUSA, F. B.; ARAUJO, M. R. A. Pastoreio de curta duração com ovinos em caatinga raleada no sertão cearense. Pesq. agropec. bras., vol. 34, n. 1, p. 135-140, 1999.

WWFBRASIL.Caatinga.Disponívelem:HTTP://www.wwf.org.br/natureza_brasileira/bioma_caatin ga/index.cfm> Acesso em: 14.10.2017.

ANDRADE, M. V. M. Dinâmica e Qualidade do Estrato Herbáceo - Subarbustivo na Caatinga do Cariri Paraibano. 2008. 183 f. Tese (Doutorado em Zootecnia) - Universidade Federal da Paraíba, Areia. 2008.

LUZ, A. R. M.; ROCHA, A. M.; ABREU, M. C. Levantamento Florístico da Vegetação Herbácea Presente em um Área de Caatinga, Gameleira dos Rodrigues, Picos-PI. In: CONGRESSO INTERNACIONAL DE DIVERSIDADE DO SEMIÁRIDO, 1., 2016, Campina Grande. Anais... p. 6. 